\title{
Las Mujeres Violentas De La Posmodernidad Cinematográfica: Aproximaciones Y Asimilaciones
}

\section{The Violent Women Of Cinematographic Postmodernity: Approaches And Assimilations}

\begin{abstract}
RESUMEN
Desde la década de 1980 las mujeres violentas se han multiplicado en la cinematografía, convirtiéndose en uno de los objetos de estudio más relevantes y polémicos de las actuales líneas de investigación de la Teoría Fílmica Feminista. El presente artículo explora la aparición masiva de estas figuras en los albores de la posmodernidad y visibiliza la existencia de una serie de fórmulas recurrentes, a través de las que estas tienden a representarse y que sirven a la Institución Cinematográfica para asimilarlas y asimilar, en definitiva, el trauma que producen

Palabras clave: mujeres violentas, asimilación, Teoría Fílmica Feminista, posmodernidad.
\end{abstract}

\begin{abstract}
Since the 1980s, the appearance of violent women in cinema has been noticeably growing, thus becoming one of the most relevant and controversial objects of study in the current research lines of Feminist Film Theory. The present article explores the massive emergence of these figures at the dawn of postmodernity, while making visible the recurring formulas through which these women tend to be represented. Furthermore, this text studies as well how the previously mentioned formulas aid the Film Institution to assimilate the figures of violent women and the social trauma they cause.
\end{abstract}

Keywords: violent women, assimilation, Feminist Film Theory, postmodernity.

\section{SUMARIO}

1.-Introducción. 2.-La posmodernidad cinematográfica y el género inerme.3.-El fenómeno de asimilación. 3.1.- (Hiper)sexys. 3.2.- Enamoradas. 3.3.- Locas. 3.4.- Traumatizadas. 3.5.Ginoides. 3.6.- Madres. 3.7.- Custodiadas. 4.- Conclusiones. -Bibliografía.

\section{1. - Introducción}

La Teoría Fílmica Feminista habría investigado incisivamente las imágenes de las mujeres violentadas de las pantallas; el seminal From Reverence to Rape: the Treatment of Women in the Movies (Haskell, 1973) certifica ya su importancia, convirtiéndose en una constante de estudio en el transcurso histórico de la disciplina. Pero desde 
la década de 1990 aparecerán una serie de materiales dedicados al análisis de las mujeres violentas, que habían empezado a emerger durante los años anteriores con la llegada de la posmodernidad cinematográfica. El interés de este particular objeto de investigación ha ido creciendo hasta la actualidad, vinculado este a la multiplicación de estas figuras a partir de la década de 2010, como así lo confirma el reciente Women Who Kill: Gender and Sexuality in Film and Series of the Post-Feminist Era (Roche y Maury, 2020).

Es necesario aclarar de inicio, no obstante, que en lo que a la investigación de la representación de la violencia en la cinematografía se refiere, estos materiales son aún los menos: anglófonos y singulares, con frecuencia centrados en el cine estadounidense, sin que existan estudios, más allá de algunos artículos ocasionales, de igual naturaleza epistemológica en el Estado español. El hilo que une a este corpus no es solo el objeto de estudio concreto, sino la lúcida intuición de que las mujeres violentas de la cinematografía son tan transgresoras como problemáticas.

Una intuición a todas luces vinculada con la existencia de un entramado normativo que trasciende a la actividad de representación y que apunta a la relación misma de las mujeres, como sujeto histórico y colectivo, con la violencia. Resulta evidente que, de manera más o menos explícita, estas figuras han resucitado el debate no resuelto en los feminismos sobre la posibilidad o deseabilidad de que las mujeres recurran al ejercicio violento: el provocador interrogante lanzado por Karen Hagberg décadas atrás, «Why the Women's Movement Cannot be NonViolent » (1978), continúa hoy vigente.

No obstante, el debate no se ha trasladado simplemente a lo que se ha venido llamando el séptimo arte, la máquina de los sueños: retirar el velo e insistir en que la Institución Cinematográfica es una industria cultural del heteropatriarcado capitalista, global y multimillonaria, aporta un contexto indispensable para el análisis de la actividad de representación que revela lo que la discusión sobre estas figuras esconde. Diciéndolo de otro modo: las mujeres violentas de las pantallas venden; el hecho no es menor pues, para vender, estas deben estar inscritas en determinadas fórmulas representacionales, resortes ambivalentes de las ansiedades y fantasías del heteropatriarcado, capaces de aliviar y excitar, asimilar, el trauma que producen. Tania Modleski apuntaba también a esta misma dinámica fetichista cuando afirmó que el cine estaría:

... ocupado cada vez más en la época post-feminista y posterior a la de los derechos civiles, por una cultura de masas que debe reconocer en un nivel las luchas políticas de las últimas décadas y en otro, más profundo, alejar la amenaza que esas luchas plantean a la estructura del poder masculino blanco. (Modleski, 1995: 117).

El concepto de Institución Cinematográfica persigue, precisamente, retener una connivencia normativa, heteropatriarcal, capaz de cuestionar la naturaleza transformadora de sus productos culturales; unos productos culturales cuidadosamente elaborados, en esta era pos-, sobre el reconocimiento de la libertad individual de las mujeres para, y esta es la clave, consumir. Es posible que este 
fenómeno de asimilación permita comprender las reacciones que las mujeres violentas de la cinematografía provocarían en las teóricas feministas, oscilando entre la celebración y el rechazo.

\section{2. - La posmodernidad cinematográfica y el género inerme}

Es verdad que las mujeres violentas siempre han existido en la cinematografía; pero los personajes del clasicismo y de la modernidad son cuantitativamente excepcionales, testimoniales, y cualitativamente menos violentas comparándolas con la presencia en número y protagonismo que van a tener estas en la posmodernidad y muy especialmente a partir de la década de 2010 que acabamos de cerrar. Aunque ellas aún son las menos, considerando la totalidad de películas, conviviendo con una amplia mayoría de imágenes de mujeres violentadas, la aparición de personajes de mujeres violentas parece ser una clara característica definitoria de lo que se ha venido llamando posmodernidad cinematográfica.

Ante las suspicacias que las mujeres violentas ofrecían, todos los estudios empezarán por investigar los distintos momentos en los que estos personajes emergieron, vinculando tales representaciones al contexto político, social, económico en el que se produjeron. Diversas teóricas localizarán así la aparición de estas figuras en tres momentos clave que, a nivel histórico, se han entendido como momentos de negociación y reconfiguración de las relaciones de género, esto es: en el escenario que siguió a la Segunda Guerra Mundial tras la incorporación masiva de las mujeres al trabajo asalariado, durante los años que posteriormente acogieron a la candente $2^{a}$ Ola y, ahora, en la actualidad y junto al devenir de la $3^{a}$ Ola posmoderna. Interpretaron así a las representaciones tanto en la dirección de si venían a constatar un deseo de emancipación de las mujeres, como si se tratara de una reacción antifeminista a los movimientos; es decir y en definitiva, como el resultado de contextos de disputa ontológica.

En este sentido, aquí se maneja una hipótesis complementaria que comprende la emergencia de estos personajes como parte de un progresivo acercamiento a una zona salvaje que Elaine Showalter (1981) conceptualizó también como aquello que había sido contenido fuera de los proyectos de modernidad: como un terreno irrepresentable, contenedor simbólico de la monstruosidad de las mujeres. Algunos teóricos del cine como Olivier Mongin (1998) y, específicamente, Gérard Imbert concebirían también la posmodernidad cinematográfica como una aproximación al terreno de lo irrepresentable; este último considera que la violencia es uno de los tres referentes junto con la muerte y el sexo, que participarán de un «[...] juego con los límites que es típicamente posmoderno, un jugar con la representación de lo prohibido [...] la tendencia a ir más allá de lo visible, de lo socialmente admitido» (2010: 337-338).

Esta perspectiva apela directamente a la existencia de un entramado normativo que trasciende a la actividad de representación en lo que a las mujeres violentas de las pantallas se refiere y que, en síntesis, puede expresarse con la norma mujeres objeto, no sujeto de violencia; de violencia, conviene indicar, conceptualizada de manera 
restringida como la acción directa, interpersonal o colectiva que intencionalmente causa daño o pretende causar daño físico contra la voluntad de quien la recibe.

Tres cuestiones apuntan a la norma como una idea radical para la investigación feminista: la primera se desprende de comprenderla como un elemento contextualmente dependiente, esto explica la convicción de que la norma puede ser combatida y transformada. Una segunda cuestión se debe a su definición como no natural y es que, precisamente, esta particular intentará pasar desapercibida en tanto norma y será, para ello, naturalizada. En tercer lugar, una última consideración procede de su carácter artificioso: la norma no deja de ser, al fin y al cabo, un artificio al que adherirse o resistirse en cada contexto; esta dinámica que es necesario retener, adherencia - resistencia, es la que explica que, de la misma manera que no todas las mujeres mantienen una relación idéntica con la opresión, no todas las mujeres mantendrán una relación normativa con la violencia misma. Se trata, en definitiva, de la posibilidad de transgredir.

Es claro que el origen de este imperativo en su formulación moderna está localizado en un reparto desigual de las cualidades humanas: agresividad y vulnerabilidad particularmente. La idea de un reparto desigual es la epistemología fundacional de las teorías feministas y del género en sí, pero más allá de esta evidencia, la expresión específica de «distribuciones diferenciales de las cualidades humanas» está originalmente contenida y conceptualizada en la reflexión de Judith Butler en Marcos de Guerra (2010), cuya tesis principal es que los marcos de interpretación mediante los que comprendemos las guerras son en sí mismos una acción de guerra; los marcos aquí son la norma, y dice la pensadora:

Si un sujeto concreto se considera por definición dañado o perseguido, entonces cualquier acto de violencia que cometa no puede registrarse como «generador de daño», puesto que el sujeto que comete actos de violencia está, por definición, imposibilitado para hacer cualquier cosa que no sea sufrir daño. A resultas de esto, la producción del sujeto sobre la base de su estatus de dañado produce entonces una base permanente para legitimar (y deslegitimar) sus propias acciones violentas. (Butler, 2010: 245).

Formular una distribución diferencial para la posibilidad de la violencia supone afirmar que existe la apariencia, en definitiva, de que las mujeres son 1) más vulnerables, que pueden ser más fácilmente agredidas y dañadas físicamente; 2) menos agresivas, que tienen menos tendencia a agredir y dañar físicamente. El resultado será la apariencia de que las mujeres, en tanto sujeto generizado en esa distribución, son seres inofensivos e indefensos, inermes. La recurrencia de esta operación concretará la norma mujeres objeto, no sujeto de violencia encargada de regular u organizar la relación de este sujeto con el ejercicio violento y servirá de base productiva de la estereotipia que permanentemente enfatiza la vulnerabilidad de las mujeres, pese a ser esta una cualidad universal común a toda especie.

El asunto que disrupta la armonía normativa, que convierte los límites en fronteras, es que este particular imperativo no es una premisa que las mujeres deban simplemente adherir o resistir: en tanto sujeto históricamente formado, la norma 
es parte constitutiva de lo que la colectividad mujeres, en definitiva, debe ser. A la luz de esta reflexión, se comprenderá la dimensión de la transgresión: cuando las mujeres son sujeto de violencia no solo transgreden la penalidad vigente contenida en el contrato social, sino que la misma ontología de género es transgredida. Se produce un desborde.

Una hipotética mulier mulieris lupus aparece, convocando a Thomas Hobbes, para personificar el terror heteropatriarcal y revelar la monstruosidad que ha permanecido escondida tras el decreto moderno de la inermidad de las mujeres. La consideración velada de que esta monstrua alberga en realidad una letalidad superior asociada a su ontología natural y no política, es un elemento funcional, es un elemento de primer orden, del heteropatriarcado y también de sus producciones culturales. Y es que el núcleo central de todo este terreno epistemológico, de este locus de poder, es una paradoja: la paradoja de lo imposible y lo prohibido que también notificó y desarrolló Lynda Hart cuando se acercó al fenómeno de las mujeres violentas de las pantallas (1994: 3-28). La paradoja de que una mulier mulieris lupus es imposible porque las mujeres no son sujetos de sí; no pueden, por lo tanto, estar insertas en relaciones de sujeto. Pero está prohibida precisamente porque es posible: porque las mujeres son sujetos de sí y están insertas en relaciones de sujeto. El locus de poder de esta particular norma asienta entonces sobre un juego fetichista de afirmación y negación, de presencia y ausencia de una monstruosidad que Michel Foucault concibió precisamente como el «derrumbe de la ley» (2007 [1999]: 61). Inscritas en este juego, las mujeres violentas empiezan a revelarse como imágenes de fantasía y ansiedad para el heteropatriarcado: este planteamiento es fundamental para comprender la necesidad institucional, en connivencia sistémica, de asimilación.

Cuando Hilary Neroni (2005) investigó la representación de las mujeres violentas de la cinematografía desde el posmarxismo y el psicoanálisis, concluiría que feminidad y violencia son elementos excluyentes en las narrativas de Hollywood; y apunta: «[...] the extraordinary lengths to which the narrative must go to explain or situate the violent woman reveals the trauma caused by her violence» (Neroni, 2005: 11). Este trauma se puede percibir en las reacciones ante la violencia real de las mujeres; aunque hay numerosos ejemplos, quizás el más claro, también el más estudiado, es el caso de las torturadoras de Abu Ghraib: la conmoción sin precedentes que suscitaron estas imágenes no podía explicarse solo por la presencia del sujeto torturador, sino por la presencia de un sujeto torturador sexuado.

Por supuesto, cuando la norma que regula la relación de las mujeres con la violencia real transita al plano de la representación, esta se condensa y se dispersa conforme a una negociación con las propias normas que organizan los textos de la Institución Cinematográfica; a saber, la irrenunciable presencia de hombres con agencia e intervención en el devenir narrativo, lo que podría expresarse del mismo modo con la particular mujeres objeto, no sujeto de la acción (violenta) representada. En este marco textual, la identificación de las asimilaciones normativas está muy relacionada con como abordarán las películas el fenómeno que comenta Janice Loreck: 
Narrative cinema is filled with moments that present the violent woman as an enigma. [...] Although a man's violence might be represented as heroic or villainous, rarely is his capacity for physical aggression depicted as problematic in and of itself. When a woman commits an act of violence, her behaviour - indeed, her very existence - causes profound unease and questioning. (Loreck, 2016: 1).

Las mujeres violentas emergen masivamente en un contexto de espectacularización, naturalización y estetización de la violencia, esto es que el ejercicio violento impregna el conjunto de la materialidad fílmica; pero esta característica no desafía en absoluto la naturaleza narrativa de los textos de mayor éxito en las audiencias y es precisamente esta narración la que ubica la violencia en la película haciéndola interpretable y, por lo tanto, significativa.

\section{3. - El fenómeno de asimilación}

Las mujeres violentas aparecen en la cinematografía posmoderna mediante fórmulas de asimilación cuya recurrencia delata la plena operatividad de un entramado normativo que las trasciende. Estos personajes, en tanto sujetos de violencia representada, han transgredido no solo la norma que regula la relación de las mujeres con el ejercicio violento, sino que en muchas ocasiones su estatus protagonista les permite transgredir también la norma textual, específica del dispositivo cinematográfico, que las convierte en objetos depositarios de la acción representada y niega su agencia o capacidad de acción sobre el devenir narrativo. Ante la transgresión, la Institución Cinematográfica desplegará una serie de resortes narrativos y discursivos: estrategias presentes en los textos cinematográficos a través de las que reconstruir, asimilar, la ontología previamente desbordada.

Evidentemente la ontología de género que decreta que las mujeres son seres naturales, no políticos, está plenamente vigente en las representaciones: la suya es una violencia salvaje y es en la misma medida, natural, no política. En este marco normativo, las motivaciones de estos personajes serán siempre emocionales, no racionales; y sus objetivos, relacionales, no individuales. Efectivamente, las mujeres no dejarán de ser sujeto por estos factores, pero estos participan de la configuración de una narrativa y de un discurso capaz, en última instancia, de anular la agencia.

Las asimilaciones se concretan en el dispositivo cinematográfico en diversos resortes que producirían fórmulas recurrentes y reconocibles, estereotipos y contraestereotipos, fruto de su uso reiterado. Tales estrategias operan en la historia y en su estructuración argumental y aparecen materializados en el soporte discursivo; están presentes en la construcción física y psíquica de los personajes, en sus motivaciones y objetivos, y en los conflictos dramáticos llegando a ocupar en ocasiones la centralidad de las tramas.

Se han identificado un total de siete fórmulas de asimilación a través de las cuales las mujeres sujeto de violencia representada son o están: 1) (Hiper)sexys, 2) enamoradas, 3) locas, 4) traumatizadas, 5) ginoides, 6) madres, o 7) custodiadas. Son tres las estrategias que operan en estas asimilaciones: la objetualización, la sustitución del sujeto y una última que permite a las mujeres ser sujetos de 
violencia bajo condiciones específicas. En cualquier caso, las tres posibilitarán la (re)producción de la norma.

La primera está dirigida a devolver a las mujeres a su normativo lugar de objetos, a saber, objetualización; la estrategia viene a ser, probablemente, la asimilación más estudiada y la más fácilmente identificable; el sujeto pasa a ser objeto. Considérese a estos efectos que, desde la Ilustración, el sujeto es por definición racional; el sujeto emocional es un sujeto inconsciente, naturalmente determinado y, en este sentido, es siempre objeto de sí mismo. Las asimilaciones que afirman a las mujeres violentas como 1) (hiper)sexys, 2) enamoradas, 3) locas y 4) traumatizadas, producen este tránsito independientemente del discurso que las sostenga.

Por otro lado, el desplazamiento del sujeto mujeres por otro sujeto que lo sustituye, es un movimento en el que la norma simplemente se suspende y deja de aplicar; es lo que ocurre a la hora de abordar la violencia de las 5) ginoides o de las 6) madres: el peso significante, simbólico, y la multiplicidad de articulaciones que de él se desprenden, desplazan la identidad de las mujeres para dejar paso a otros sujetos cuyas sujecciones ontológicas acaban por reforzar los marcos normativos, bien por las motivaciones que llevan a las mujeres a su adhesión a la violencia, bien por ser resultado del quehacer científico de los hombres, respectivamente.

En cuanto a las mujeres 7) custodiadas se trata de una imagen de transgresión que sujeta el ejercicio de su violencia a determinadas condiciones que confirman y refuerzan el poder heteropatriarcal.

Vaya por delante, antes de continuar, que el hecho de que estas representaciones sean asimilaciones, no las convierte en incapaces de provocar identificaciones transgresoras para las audiencias; en realidad, como productos culturales de la Institución Cinematográfica estos deben ser consumibles. La magia del arte, el truco de la máquina, es que se trata de una transgresión controlada.

\section{1. - (Hiper)sexys}

Cuando las mujeres ejercen violencia y amenazan la inermidad, amenazan también aquello que las hace deseables. Así, no es de extrañar que una asimilación normativa habitual consista precisamente en reconducir los actos violentos de las mujeres hacia la consecución de ese deseo.

Hipersexualización para diferenciarla de la sexualización transversal presente en la habitual actividad de representación de la cinematografía; el prefijo hiper permite identificar más claramente esta particular estrategia que eleva la sexualización a la narratividad fílmica. No se trata solo del grado de sujección de la apariencia al deseo patriarcal en el plano estético, sino de las repercusiones narrativas que tal grado de sujección tiene en la construcción misma de los personajes: de cómo limita su agencia. El tránsito del ejercicio es sencillo: la parte por la que son sujeto de violencia es discursiva y simbólicamente sustituida por la parte en la que son objeto de deseo. En esta operación, sus objetivos y motivaciones pierden atención e importancia, convirtiendo las acciones violentas en un receptáculo para el goce de la mirada patriarcal: un fetiche que concreta la fantasía y la ansiedad, la afirmación 
y la negación; prueba del movimiento es la inverosimilitud de un vestuario nada adecuado para unas heroínas que enfrentan complicados escenarios de conflicto físico. Paradójicamente, esta hipersexualización aparece en muchas ocasiones para sustituir, precisamente, las escenas de sexo con la protagonista violenta; esto explica por qué se experimentó tanto con personajes de mujeres afroamericanas a las que el sujeto blanco racista temía desear.

La estrategia se extiende, muy especialmente, por los géneros de acción y ciencia ficción afectando tanto a personajes principales como secundarios; fenómeno del que da cuenta la cantidad de materiales teóricos que se dedican a analizarlo y denunciarlo.

Entre las películas de acción destacará la secundaria Letty Ortiz, interpretrada por Michelle Rodríguez, en The Fast and the Furious (Rob Cohen, 2001) y su posterior saga; en el mismo género y protagonistas son las Charlie's Angels (Joseph McGinty, 2000) y, por supuesto, la famosa arqueóloga Lara Croft; de hecho, la Lara Croft de Angelina Jolie en Tomb Raider (Simon West, 2001) y The Cradle of Life (Jan De Bont, 2003) recibiría tantas críticas por la hipersexualización del personaje que su versión más reciente, interpretada por Alicia Vikander en la homónima Tomb Raider (Roar Uthaug, 2018), ya no puede interpretarse en este marco con la misma facilidad. También el mundo Grindhouse con Planet Terror (Robert Rodríguez, 2007) y Death Proof (Quentin Tarantino, 2007) utiliza esta estrategia.

En lo que respecta a la ciencia ficción, protagonistas como Alice Abernathy, interpretada por Mila Jovovich en Resident Evil (Paul W.S. Anderson, 2002) y la saga que le siguió, o la Selene de Kate Beckinsale en Underworld (Len Wiseman, 2003) y también su posterior saga, son representativas de esta asimilación. Específicamente, en el mundo de las super, Catwoman (Jean C. Comar, 2004) sería de las primeras películas en tener a una mujer como protagonista e hipersexualizada; otras cintas como Fantastic Four (Tim Story, 2005) o The League of Extraordinary Gentlemen (Stephen Norrington, 2003), esta a pesar de su título, reservarían a las mujeres papeles secundarios.

No obstante, la estrategia no solo estará presente en estos géneros; por ejemplo, Jeffrey Brown (2001) analiza, trayendo a colación a Laura Mulvey, las películas de stripper-revenge, una versión de los rape-revenge, enfatizando que las strippers matan a los hombres que las miran. Entre este tipo estarían cintas como Showgirls (Paul Verhoeven, 1995) en la que la hipersexualización de los personajes juega un papel fundamental, trascendiendo a sus conflictos y protagonizando, en definitiva, la película.

Para un ejemplo próximo está el personaje de Amaia, interpretado por Mélanie Doutey en El Lobo (Miguel Courtois, 2004), película que cuenta la historia del agente infiltrado que desestabilizó a ETA político-militar en 1975. En la escena de sexo entre Amaia y el protagonista, Courtois le puso a la primera un pasamontañas y al segundo lo representó como un hombre atrapado entre la fantasía y la ansiedad: afirmación y negación. El pasamontañas no pasa inadvertido como el primer elemento fetichista capaz de anular la identidad de Amaia al tiempo que deja al descubierto el resto de su cuerpo desnudo: la escena confirma como imprescindible 
el ejercicio de fetichización tanto para construir el trauma de ETA, como para liberarse de él.

Por último, en La Femme Nikita (Luc Besson, 1990) se sintetiza muy bien esta asimilación, pues el arco de transformación de la protagonista se marca con escenas que tienen lugar en el cuarto de una maquilladora quien le dice la primera vez que la ve: «Si nuestros esfuerzos son reiterados y mutuos y si el cielo es generoso, acabaremos por conseguir darte forma humana. Etapa intermedia y, sin embargo, necesaria antes de convertirte en la esencia del hombre: en una mujer» (00:25:5700:26:16). En la escena que sitúa el inicio de la segunda parte del metraje es la propia Nikita quien se maquilla frente al espejo y es ya un objeto de deseo y un elemento activo de la mecánica escópica: dejó de ser la monstrua violenta del principio de la película para convertirse ya en una mujer, en una asimilación.

\section{2. - Enamoradas}

Esta particular es también frecuente y se fundamenta en la teoría de las mujeres enamoradas: una teoría de dependencia que entiende por enamoradas cegadas, manipuladas y toda una serie de términos que configuran la idea de un sujeto inconsciente, objeto de sí mismo y, esto es de gran relevancia, obligatoriamente heterosexual. Esta obligatoriedad lesbófoba se sostiene en la cinematografía en dos premisas: la primera, que la autoridad racional de los hombres es la única capaz de cegar o manipular racionalmente a las mujeres; que una mujer ciegue o manipule es necesariamente patológico. Por otro lado y en segundo lugar, porque la heterosexualidad es un elemento de primer orden en el funcionamiento del heteropatriarcado, colocando lo ajeno a la heteronorma en un territorio de insuficiencia; debido a esto, el cine no representa preferiblemente relaciones fuera de la norma heterosexual como argumentos secundarios de las películas debido a la carga significante que la Institución Cinematográfica le presupone: si hay una relación lésbica, esta tiene que ser el centro de la trama porque la norma considera que esta debe ser, de alguna manera, explicada.

El dibujo de las mujeres enamoradas es un dibujo de inconsciencia que las aproxima a las locas; de hecho, el movimiento de una y otra estrategia es el mismo y la línea que las separa es, en algunas películas, enormemente sutil: en ambas emerge un sujeto sin agencia ni responsabilidad sobre sus acciones. En este delirio heteropatriarcal, el sujeto inconsciente se explica a partir de las motivaciones y objetivos que, se esgrime, llevaron a las mujeres a adherir la violencia: siempre de carácter emocional, privado y relacional. Esto explica por qué es más fácil identificar la estrategia en películas en las que las mujeres participan de organizaciones con un objetivo que responde a un bien mayor; piénsese, por ejemplo, en personajes como Evey, interpretada por Natalie Portman en la conocida V For Vendetta (James McTeigue, 2006): el texto necesita realizar un esfuerzo superior y específico para vincular la adhesión de la protagonista a una emoción; sus posibles objetivos políticos para derrocar al régimen resultan eclipsados por su misión afectiva y el carácter inexorablemente relacional de estos. 
Las mujeres violentas enamoradas no tendrán agencia más allá del amor mismo; la vinculación emocional con los hombres conferirá significación y, en última instancia, legitimación a su violencia. La estrategia adquiere su fórmula más identificable en las películas de parejas asesinas, una constante en la historia de la cinematografía desde Deadly Is the Female - Gun Crazy (Joseph H. Lewis, 1950), a la emblemática Bonnie E Clyde (Arthur Penn, 1967), pasando por The Honeymoon Killers (Leonard Kastle, 1969), The Getaway (Sam Peckinpah, 1972), Badlands (Terrence Malick, 1973), True Romance (Tony Scott, 1993) y hasta la insigne Natural Born Killers (Oliver Stone, 1994) y la más reciente Mr. and Mrs. Smith (Doug Liman, 2005).

En muchas de estas películas, todas ellas con enamoradas y violentas mujeres como co-protagonistas, estará presente la idea de que ellas son, en realidad, más letales que sus compañeros de viaje; el simbólico no se disrupta: se abre en su radicalidad. Probablemente ninguno de los dúos, ni siquiera el impacto que en su momento tuvo Bonnie $\mathcal{E}$ Clyde (1967), conseguiría superar la potencia destructora de Natural Born Killers (1994) que convertiría a Mallory en una de las mujeres violentas más famosas de la historia del cine. Tras la autoridad de la figura masculina, es posible liberar la natural violencia de las mujeres hasta hacerlas presas de sí mismas; por esto, con frecuencia, estos personajes experimentan un tránsito desde estar enamoradas a estar, y ser asimiladas como y en definitiva, locas.

\section{3. - Locas}

Ciertamente próxima a la asimilación de las mujeres enamoradas, pero la distinción es fructífera siendo aquí la patologización el elemento de énfasis narrativo. En este caso es la locura la que convierte a las mujeres en un sujeto inconsciente, objeto de sí mismas, sin agencia ni responsabilidad sobre sus acciones.

La patologización ha sido siempre la interpretación estrella para afrontar a las mujeres transgresoras y se basó en la afirmación de estas en tanto sujeto natural; se trata de un sujeto cuyas capacidades racionales están necesariamente distorsionadas por unas emociones que se aparecen como desatadas e incontrolables: están abandonadas a su naturaleza. Así, una característica de esta estrategia y que la distingue de las demás es que los objetivos de los personajes aparecen en muchas ocasiones distorsionados: ejercen una violencia que no tiene fin porque están en la violencia. Por tal motivo, esta asimilación es habitual en el cine histórico, social y en biopics sobre mujeres implicadas en organizaciones armadas: Gudrum en la película Der Baader Meinhof Komplex / R.A.F. Facción del Ejército Rojo (Bernd Eichinger, 2008) puede interpretarse a través de esta estrategia.

Las motivaciones que llevan a las mujeres locas a la violencia serán siempre emocionales, privadas y relacionales, ya que tienden a vincularse a una frustración con su destino natural y reproductivo. En este sentido específico es la Rebeca de The Hand that Rocks the Cradle (Curtis Hanson, 1992) o la Alex de Fatal Attraction (Adrian Lyne, 1987); sobre ambas reflexiona Barbara Creed y dice de la última: 
[...] the heroine (an unmarried career woman) is transformed into a monster because she is unable to fulfil her need for husband and family. In a number of recent - and very popular- films about female psychotics, the killer is an outsider, a lone woman who muders to possess what has been denied her: family, husband, lover, child. (Creed, 1994: 122).

Aunque se podría pensar que esta estrategia es habitual y transversal en la cinematografía, no lo es tanto: la monstruosidad amenaza a la locura; para que estas figuras sean una asimilación, los personajes deben estar dentro del canon de deseabilidad patriarcal: deben ser consumibles. Esta es la idea que vertebra la archifamosa Basic Instinct (Paul Verhoeven, 1992); resulta muy evidente que ante el interrogante de si Catherine Tramell es o no la asesina, el juego entre la patologización y la monstruosidad protagoniza el desarrollo y es evidente que tal juego no sería posible si Sharon Stone no respondiese al canon de deseabilidad patriarcal; en una aproximación muy interesante, «Sharon Stone's (An)Aesthetic», Susan Knobloch (2001) analiza la figura de la actriz y su tendencia a representar la ambivalencia de las mujeres violentas siendo quien de interpretar la ambigüedad víctima / victimaria que, Knobloch defiende, está presente en todas sus películas, incluyendo esta en particular.

Pero, yendo más allá y casi se apuntaría que clave: el primer elemento que caracteriza la representación de Tramell, concretando también una idea ambivalente, es que se trata de un personaje bisexual; que también se relacione afectiva y sexualmente con mujeres es el simbólico sobre el que el texto vertebra su patologización primero y su violencia después; y es que esta asimilación tendió a recoger las distorsiones no contenidas en la teoría de las mujeres enamoradas, enfatizando la patologización de los personajes que habitaban fuera de la norma heterosexual.

\section{4. - Traumatizadas}

Las películas que utilizan esta estrategia suelen tener como protagonistas a mujeres vengativas que responden a la violencia, específicamente física, de los hombres; esto explica la omnipresencia de estas figuras a lo largo de la cinematografía constituyendo un popular y reconocible grupo y convirtiendo a esta asimilación en una de las más habituales.

Esta estrategia aparece para encerrar a los personajes de las mujeres en la agresión y en el trauma: además de sufrir la violencia, no pueden salir de ella. Esta atadura, ellas no deciden, cuestiona su agencia y la responsabilidad sobre sus actos, convirtiéndolas en sujetos inconscientes, de nuevo, objetos de sí mismas. Se trata de un sujeto natural de motivaciones emocionales pero con un objetivo individual, siendo en ocasiones la única asimilación que permite, legitima, a las mujeres a ejercer violencia por y para ellas mismas: Death and the Maiden (Roman Polanski, 1994) es un famoso ejemplo.

Los mensajes ideológicos implícitos en esta asimilación son verdaderamente potentes: primero se define lo que es una agresión vinculándola con frecuencia a una 
concepción muy restrictiva y espectacularizada como brutal. Después se legitima, con base en esta definición, el ejercicio de la violencia con un objetivo individual: describiendo en que condiciones puede una mujer vengarse violentamente de los hombres. Por último, se elude un hipotético proceso de duelo, sanación y recuperación de las mujeres; de hecho, las mujeres suelen vivir en solitario en estas películas y tampoco le cuentan la agresión sufrida a otras personas: todo un referente fuerte.

Como se puede intuir, el rape-revenge ${ }^{2}$ es el género emblemático de este tipo de narraciones cuyos orígenes hay que ubicar en el cine de explotación estadounidense de la década de 1970 para extenderse, ya en la posmodernidad cinematográfica, al cine comercial. Su nombre responde a su singular estructura narrativa que presenta a una mujer inerme, a menudo virgen, que es violada por uno o varios hombres; se produce entonces una transición de objeto a sujeto de violencia: movimiento aterrador para el heteropatriarcado que confirma la dinámica ansiedad - fantasía y que tiende a culminar, para insistir en dicha dinámica, en una castración bajo una promesa sexual falsa; de hecho, Barbara Creed (1994: 123) utiliza este género para desarrollar la figura de la femme castratrice que, apunta, activará la simpatía del público y raramente será castigada.

Las polémicas que rodean al rape-revenge, con admiradoras y detractoras, incluso en el seno de la Teoría Fílmica Feminista, resultan interesantes al comprender que la especificidad de su narrativa reside precisamente en la claridad con la que la propia política textual representa la transgresión de objeto a sujeto de violencia. I Spit On Your Grave (Meir Zarchi, 1978) o Ms. 45 (Abel Ferrara, 1981) son dos de las precursoras del género y están insertas en esta categoría: ambas presentan escenas de anticipación erótica en las que el goce patriarcal es privilegiado, ya que, en el tránsito de objeto a sujeto, las mujeres son cuidadosamente erotizadas. Precisamente para garantizar la consecución de ese goce patriarcal, sus cuerpos nunca se transforman: cambia la actitud, cambia el vestuario, pero la apariencia de inermidad es respetada en aras del deseo.

\section{5. - Ginoides}

Las «ginoides» no son mujeres y no lo son aunque se idenfiquen como tal; ante el funcionamiento de la norma que aquí ocupa, esta particular sustitución anula la posición de sujeto de violencia para las mujeres, anulando la enunciación de la norma y suspendiendo una posible agencia. Que se identifiquen como tal, que sean, efectivamente, ginoides, no desafía en absoluto este razonamiento: el cuerpo eléctrico encierra cuestiones epistemológicas de calado. El primer síntoma es, por supuesto, la necesidad misma de la cinematografía de viabilizar, permanentemente, una identificación de género de estas máquinas mediante su apariencia o atributos o reservándoles determinadas ubicaciones en las tramas.

La película Samurai purinsesu: Gedô-hime / Princesa Samurai (Kengo Kaji, 2009)

2 Para un análisis del rape-revenge en la cultura popular: The New Avengers: Feminism, Femininity and the Rape-revenge Cycle (Read, 2000). 
puede clarificar esta estrategia: una mujer sobrevive a un ataque en el que asesinan a varias de sus compañeras; esta mujer es encontrada por un científico que le da un nuevo cuerpo de ginoide con el que sí podrá aniquilar a sus agresores. Este argumento condensa dos puntos de interés para esta asimilación: por un lado, la necesidad de desplazar el cuerpo de las mujeres para ejecutar la violencia al tiempo que una serie de atributos -que el heteropatriarcado ha decretado lo identifican como tal-son reservados; por otro, la conversión de este cuerpo en una tecnología resultado del quehacer científico de los hombres.

Las mujeres son negadas, en tanto el cuerpo es desplazado por la tecnología, y afirmadas al mismo tiempo, en tanto la letalidad ontológica es reservada; este juego convierte a las ginoides en fetiches insertos en un ámbito de confirmación de poder heteropatriarcal como es el ámbito científico-técnico: tal y como vaticinaron Mary Shelley o la propia Thea Von Harbour con Metropolis (Fritz Lang, 1927), estas máquinas encerrarían el gran anhelo heteropatriarcal de que los hombres puedan, en última instancia, cancelar la diferencia y (re)producir la vida; pero va más allá de Shelley y Von Harbour, porque cuando estas ginoides son, efectivamente, máquinas de matar al servicio de la lógica instrumental heteropatriarcal, ya no se trata de cancelar la diferencia sino de someterla: someter a las mujeres es someter a la naturaleza, dominar la violencia de las primeras será dominar la violencia de la gran Otra.

Las ginoides violentas son recurrentes en la historia de la cinematografía, extendiéndose por varios géneros y especialmente en la ciencia ficción; desde la letal Prix de Blade Runner (Ridley Scott, 1982) hasta la más reciente protagonista de Ex Machina (Alex Garland, 2015), pasando por la archifamosa Terminatrix de Terminator 3: Rise of the Machines (Jonathan Mostow, 2003) conscientemente generizada por el director quien afirmó que «lo más mortífero y terrible tenía que ser una mujer» (Novell, 2005: 175). No son mujeres, son simples remanentes del heteropatriarcado, fantasías y ansiedades eléctricas.

\section{6.- Madres}

Esta asimilación es absolutamente tranversal a todos los géneros cinematográficos y es que la Madre va a ser una de las figuras más recurrentes en lo que a la representación de las mujeres violentas se refiere. Para lo que aquí ocupa, las madres imaginadas por el heteropatriarcado no son mujeres; de hecho, el símbolo posibilita hacer de las madres un otro sujeto histórico, concreto y diferenciado que es además, por definición, relacional. Para explicar esta controvertida perspectiva, se dirá que el peso significante de la Madre es tal que desplaza al significante mujeres de la ecuación; en este ejercicio, el sujeto es sustituido por lo que la norma mujeres objeto, no sujeto de violencia simplemente deja de aplicar.

Esta asimilación suele ir siempre aislada de las demás porque las madres no son sexys, ni están enamoradas, ni locas; porque precisamente, ser madre para el heteropatriarcado es vivir ese límite: ser solo madre. En la cinematografía, ese límite es un elemento estructurante de los textos: quizás el ejemplo más relevante 
y también el más estudiado se encuentre en la película The Long Kiss GoodNight (Renny Harlin, 1996) cuyo conflicto dramático es precisamente la pugna entre la identidad de la madre y la identidad de la mujer (violenta).

No es una coincidencia que la creación del recurso de anticipación erótica que se convertiría en un resorte recurrente de los rape-revenge, se experimentase por vez primera con una madre: en la película The Last House on the Left (Wes Craven, 1972), es la madre de una de las víctimas quien se venga y es el peso simbólico de la figura, que escapa a la erotización, lo que facilita desde el principio la identificación de la escena de la felación como una trampa; un engaño del que espectadoras y espectadores participan, esperando el momento de la violencia y desplazando, a través de este sujeto, un posible goce escopofílico.

Este límite explica también por qué en el Volumen 1 de Kill Bill (2003), Quentin Tarantino privilegió la identificación del personaje interpretado por Uma Thurman como «La Novia» en lugar de «La Madre», a pesar de que la escena de apertura de la película sitúa claramente ambas identidades como elementos motivacionales: Thurman, con un vestido blanco y embarazada, tirada en el suelo de la iglesia y recubierta de sangre es el preludio de la venganza. En dirección contraria al caso de la película de Craven y para permitir el goce escopofílico patriarcal, ella debía ser «La Novia» y no «La Madre»; imposible pensar que se trata de una elección inocente pues Tarantino cuidó de manera explícita el uso de los nombres de la protagonista, hasta el punto de que su nombre propio aparece censurado con un pitido durante toda la primera película para ser revelado en la segunda. Dato significativo también que sea solo en el desenlace de la historia, ya en el Volumen 2 (2004), cuando su hija, finalmente viva, la llame, identificando al personaje por primera y única vez como madre.

La particularidad de esta respecto de las demás asimilaciones, es que esta funciona como una estrategia de legitimación, en la que la violencia de las madres es aprobada, dirigida, no obstante, a reforzar el marco normativo, porque de la afirmación de la violencia de las madres, de sus motivaciones y objetivos, se desprende la negación de la violencia para las mujeres; de hecho, las madres sujeto de violencia sí pueden ser idolatradas siempre y cuando respondan «[...] a su vocación natural: el heroísmo femenino corresponde a los valores propios de las mujeres, como la fidelidad, y son valores defensivos más que agresivos» (Castells, 2012: 93). Así, si las motivaciones que llevaron a la madre a su adhesión a la violencia están claramente relacionadas con la defensa del statu quo y con la protección de la integridad de la familia, sin importar si es el patriarca quien la amenaza, las acciones son legitimadas; en este sentido, tales motivaciones son siempre emocionales, privadas y relacionales.

Cuando el éxito de la familia heteropatriarcal se ve frustrado y esto se incorpora activamente a la narración como detonante del conflicto dramático, las madres protagonizarán películas de venganza en las que son auténticas heroínas de una violencia positivizada que activará los mecanismos de identificación de las audiencias. Es lo que ocurre en las últimas películas de Fatih Akin o Steve McQueen, Aus dem Nichts / En la sombra (2017) y Widows (2018), respectivamente: son textos 
distintos pero ambos están protagonizados por madres cuya identidad se ha visto destruida o amenazada, desatando la violencia.

Parece claro, entonces, que para poder establecer esta asimilación, la acción no puede desafiar a la propia ontología del sujeto; por ejemplo, la inconcebilidad del acto infanticida provoca un desplazamiento inmediato de la madre a la monstrua tan habitual del cine de terror. El juego con este límite estructura Dolores Claiborne (Taylor Hackford, 1995): la protagonista, que da nombre a la película, es acusada de un asesinato, lo que provoca que su hija Selena vuelva a su pueblo natal, después de años sin verse, para intentar probar su inocencia. Para reconstruir el vínculo entre las dos, emprenden un retorno al pasado y a la supuesta muerte accidental del padre de Selena. Tanto la elección de Kathy Bates para interpretar a Dolores -conviene no olvidar que cinco años antes Bates había protagonizado Misery (Rob Reiner, 1990)-, como el desarrollo de la trama, proponen un juego permanente entre la maternidad y la monstruosidad; invitando a espectadoras y espectadores a intentar averiguar la naturaleza de la protagonista y de sus motivaciones. En una de las primeras escenas, un policía entra en la sala de interrogatorios de la comisaría donde Dolores está detenida; ella está de pie, colocando unas tazas aquí y allá y mantienen la siguiente conversación: «¿Qué hace? / Adecentar un poco este maldito desorden, eso hago. Esto está hecho una pocilga. / Dolores es usted una sospechosa, no la señora de la limpieza» (00:10:57-00:11:08). Es evidente que acaban de presentarle al público una definición de sujeto extremadamente explícita en la que los límites que encierran a la maternidad, encierran también a la historia.

Con todo, es importante destacar que no es necesario que los personajes sean de facto madres para ser asimiladas como tal, es suficiente con que ocupen su posición simbólica: por ejemplo, es clave que la película The Hunger Games (Gary Ross, 2012), la primera de la saga que le sigue, dedique varios minutos de metraje a caracterizar a la madre de la protagonista, Katniss Everdeen interpretada por Jennifer Lawrence, como una mujer vulnerable y frágil incapaz de proteger a la hermana pequeña de Katniss y motivando que esta se sacrifique para salvarla. El sacrificio no solo explica los actos violentos del personaje de Lawrence en defensa de la familia, sino que la coloca en la posición misma de la madre ausente; el truco permite al texto legitimar la violencia al tiempo que mantiene deseable a la protagonista: pudiendo ser sexy, enamorarse y, en definitiva, sobrepasar el límite de la definición simbólica.

Este caramelo envenenado del heteropatriarcado es toda una concesión en aras de continuar sosteniendo una posición estructural mucho más fuerte: la consecución de las madres de su destino ontológico justifica el uso de la violencia si fuese necesario porque se entiende que las madres no tienen otra opción. Quizás esto explique también por qué son las asesinas por excelencia de la cinematografía del Estado español cuya relevancia histórica señala Barbara Zecchi (2014: 321-322).

\section{7. - Custodiadas}

Omnipresente estrategia de la cinematografía, esta asimilación permite a las mujeres un estatus de sujeto de violencia representada pero bajo supervisión 
de la autoridad heteropatriarcal. Consiste en colocar junto a la protagonista, habitualmente una mujer joven, a un hombre: el guardián de la violencia de las mujeres. Este guardián tiene la función de gestionar su capacidad de agresión, administrarla, organizarla y, en última instancia, legitimarla; la figura permite, en sentido estricto da permiso, a los personajes de las mujeres para realizar un tránsito desde ser objetos a ser sujetos de violencia, adquiriendo entonces un objetivo y entidad dramática. Resulta evidente que, en este ejercicio de confirmación del poder heteropatriarcal, los marcos normativos quedan reforzados.

El guardián tiende a ocupar la posición simbólica del padre en las tramas, pudiendo ser este efectivamente o no; para facilitar la relación paterno-filial, las mujeres suelen ser huérfanas y, en muchas ocasiones, él es el encargado de entrenarlas en la violencia como sucede en Million Dollar Baby (Clint Eastwood, 2004) o en la película de título metarreflexivo Final Girl (Tyler Shields, 2014)3. En este sentido, la figura del guardián encierra una alianza en la que las mujeres ceden su lealtad a los hombres a cambio de que estos les leguen el ejercicio de la violencia; de esta manera, detrás de las acciones de las protagonistas se encuentra siempre una motivación emocional, el guardián, o una condición, la del guardián, supervisada. Nótese que la contrapartida es una rara avis: esta sería la «M» de la saga de James Bond, interpretada por Judi Dench desde Goldeneye (Martin Campbell, 1995) hasta Skyfall (Sam Mendes, 2012), que ocupará también la posición simbólica de madre de Bond.

El rol es transversal y, aunque probablemente haya pasado inadvertido, aparece en muchas de las películas revisadas hasta el momento como The Long Kiss GoodNight (1996) o Charlie's Angels (2000) en la que una voz en off advierte al inicio: «Ellas llegan más lejos que nadie. Hacen lo que nadie más puede hacer. Por eso, cuando solo queda un último recurso, hay que acudir a ellas. Pero solo me obedecen a mí, me llamo Charlie» (00:00:20-00:00:30); y es que la figura del guardián sería particularmente frecuente en el género de acción, son los padres de The Italian Job (F. Gary Gray, 2003) y de Hanna (Joe Wright, 2011) o el Maestro Ruso de Salt (Phillip Noyce, 2010).

El director Luc Besson es un experto en los relatos con gestor, ya desde el reclutador de La Femme Nikita (1990) -el remake Point of No Return (John Badham, 1993) lo mantiene también- o Léon (1994) como mentor de tiros de Mathilda. No obstante, resulta especialmente interesante que mantenga la figura décadas después, en su reciente Lucy (2014): interpretada por Scarlett Johansson, la protagonista es obligada a portar en su cuerpo una nueva droga que accidentalmente le conferirá poderes extraodinarios. Lucy es dibujada como una «chav», una «choni», que con la sustancia adquiere de repente unas capacidades intelectuales y físicas supremas

3 2. El título se debe a la figura de la final girl, la superviviente del cine de terror producido a partir de la década de 1980, concebida por Carol Clover en el emblemático Men, Women and Chain Saws. Gender in the Modern Horror Film (2015 [1992]) en cuyo prefacio de la edición de 2015 de Pricenton Classic, la autora manifestará que su libro tendió a malinterpretarse. Clover argumenta que ella no conceptualizó a la final girl como una mutación positiva del estatus de las mujeres en las películas, sino como una actualización de las nuevas sujecciones del goce patriarcal por aquel entonces; esta idea aproxima la final girl de Clover a la idea misma de asimilación. 
convirtiéndose en una tecnología divina: en el gran cerebro. En el medio de esta pesadilla feminista para el heteropatriarcado, aparece el guardián: Samuel Norman, Morgan Freeman, al que el relato encomendará gestionar las nuevas habilidades de Lucy. La película se basa en la lógica arendtiana de a más poder, menos violencia; de hecho, la protagonista no es, comparada con sus coetáneas posmodernas, tan violenta: cuanto más accede ella al poder del conocimiento menos violencia ejerce y más fácilmente la ejerce y, aún así, Besson decidió que la película, y específicamente Lucy, necesitaba de un supervisor.

\section{4. - Conclusiones}

Todas estas asimilaciones se producen, excepto en algún caso expuesto, de manera indiscriminada; de hecho, una misma película, un mismo personaje y una misma acción, podría asimilarse, en definitiva, bajo distintas estrategias al mismo tiempo pero siempre con la finalidad que comenta Hilary Neroni «[...] if we can dissociate her from all other women, then we can protect ourselves from the trauma that she represents» (2005: 24). La centralidad que en este trauma tiene el desafío al estatuto de inermidad de las mujeres es claro y, a este respecto, se espera que se haya notificado que todos los títulos citados o comentados se corresponden con películas que las mujeres no dirigieron. Y es que hay otro hilo que conecta a todos los estudios que investigaron las imágenes de las mujeres violentas que es que, al atender exclusivamente a la representación, han prescindido de vincularlas al sujeto que las produce. Esta es otra característica común de estos materiales: ninguno de ellos reflexiona sobre que la práctica totalidad de los personajes violentos que analizan no están representados por, en definitiva, mujeres; se ha obviado la dimensión contextual de la Institución Cinematográfica que niega a las mujeres ser sujetos de representación y particularmente, ser sujetos de representación de violencia.

Las mujeres violentas que aquí se han comentado son productos ambivalentes, fantasía y ansiedad, del sujeto normativo de representación. Es posible que esto explique parte de las resistencias de algunas teóricas feministas a celebrar a estas figuras; de algunas, porque sí hay numerosas voces -Creed (1994), Neroni (2005) o Loreck (2016) - que enfatizan el potencial subversivo que estas representaciones poseen para provocar identificaciones transgresoras.

Lo interesante es que son precisamente las autoras vinculadas al mundo de la autodefensa feminista, como Ellen Snortland (1998) o Martha McCaughey (1997) las que celebran sin fisuras a estos personajes. No resulta llamativo que esta última editase junto a Neal King el famoso Reel Knockouts: Violent Women in the Movies (2001): parece evidente que la trayectoria de McCaughey siguió la sospecha de que las películas podrían estar influyendo en la posibilidad o imposibilidad de las mujeres de responder violentamente a una agresión. Tal y como Snortland explicita «[...] a female warrior image can and does make a difference to women's perception of female defensive ability» (1998: 164).

El debate está servido y es posible augurar que este particular objeto teórico continuará en los años que siguen despertando pasiones y discusiones para la 
política cultural feminista como parte de una tarea superior extremadamente compleja: la de extraer a las mujeres de la posición de víctimas; compleja porque, hay que hacerlo mientras, y en definitiva, las violencias continúan.

\section{Bibliografía}

Brown, Jeffrey (2001). «If Looks Could Kill: Power, Revenge, and Stripper Movies» en McCaughey, Martha y Neal King (eds.) (2001). Reel Knockouts: Violent Women in the Movies, Austin: University of Texas Press, pp. 52-77.

Butler, Judith (2010). Marcos de guerra: las vidas lloradas, Barcelona: Paidós Ibérica.

Castells, Irene (2012). «Mujeres en revolución. La participación femenina en la Revolución Francesa de 1789» en Molas Font, Maria Dolors (ed.) (2012). De las mujeres, el poder y la guerra, Barcelona: Icaria, pp. 81-95.

Clover, Carol (2015 [1992]). Men, Women and Chain Saws. Gender in the Modern Horror Film, Princenton: Princeton University Press.

Creed, Barbara (1994). The Monstrous-Feminine: Film, Feminism, Psychoanalysis, London: Routledge.

Foucault, Michel (2007 [1999]). Los anormales. Curso en el Collège de France (19741975), Buenos Aires: Fondo de Cultura Económica.

HagberG, Karen (1978). «Why the Women's Movement Cannot be Non-Violent» en Heresies Magazine, Vol. 2No6, p. 44. Disponible en: http:/ / heresiesfilmproject.org/ wp-content/uploads/2011/10/heresies6.pdf (Fecha de consulta: 29/06/20).

Hart, Lynda (1994). Fatal Women: Lesbian Sexuality and the Mark of Aggression, New Jersey: Princeton University Press.

Haskell, Molly (1973). From Reverence to Rape: the Treatment of Women in the Movies, New York: Penguin.

IMBERT, Gérard (2010). Cine e imaginarios sociales, Madrid: Cátedra.

KNobloch, Susan (2001). «Sharon Stone's (An)Aesthetic» en McCAugheY, Martha y Neal KING (eds.) (2001). Reel Knockouts: Violent Women in the Movies, Austin: University of Texas Press, pp. 124-143.

LoREcK, Janice (2016). Violent Women in Contemporary Cinema, New York: Palgrave Macmillan USA.

McCaughey, Martha (1997). Real Knockouts: The Physical Feminism of Women's Self Defense, New York: New York University Press.

McCaughey, Martha y Neal KING (eds.) (2001). Reel Knockouts: Violent Women in the Movies, Austin: University of Texas Press.

ModLESKI, Tania (1995). «El cine y el continente oscuro: raza y género en los filmes populares» en Colaizzi, Giulia (ed.) (1995). Feminismo y teoría fílmica, Valencia: Episteme, pp. 109-134.

Mongin, Olivier (1998). Violencia y cine contemporáneo. Ensayo sobre ética e imagen, Barcelona: Paidós Comunicación.

Neroni, Hilary (2005). The Violent Woman. Feminity, Narrative, and Violence in Contemporary American Cinema, Albany: State University of New York Press. 
Novell, Noemí (2005). «De Terminator a Terminatrix: representaciones y estereotipos de género» en Lectora: revista de dones i textualitat, No 11 , pp. 171-180. Disponible en: https://dialnet.unirioja.es/servlet/articulo?codigo $=2229646$ (Fecha de consulta: 29/06/20).

ReAD, Jacinda (2000). The New Avengers: Feminism, Femininity and the Rape-revenge Cycle (Inside Popular Film), Manchester: Manchester University Press.

Roche, David y Cristelle Maury (eds.) (2020). Women Who Kill: Gender and Sexuality in FIlm and Series of the Post-Feminist Era, London: Bloomsbury Academic.

Showalter, Elaine (1981). «Feminist Criticism in the Wilderness» en Critical Inquiry, Vol. 8 No2, pp. 179-205. Disponible en: https://www.journals.uchicago. edu/doi/abs/10.1086/448150?mobileUi=0\& (Fecha de consulta: 29/06/20).

SNortland, Ellen (1998). Beauty Bites Beast, California: B3 Books.

ZECCHI, Barbara (2014). La pantalla sexuada, Madrid: Cátedra.

Recibido el 29 de junio de 2020 Aceptado el 8 de septiembre de 2020

BIBLID [1132-8231 (2020): 73-91] 